TABLE III.-Proximate ANalysis Calculated for the Materials in Their Natural Moist Condition.

\begin{tabular}{|c|c|c|c|c|c|c|c|c|c|}
\hline \begin{tabular}{l}
$\bar{\Xi}$ \\
\multirow{2}{*}{}
\end{tabular} & $\frac{5}{30}$ & 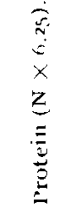 & 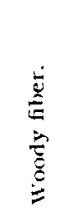 & $\stackrel{3}{3}$ & $\stackrel{\dot{x}}{\vec{x}}$ & $\frac{\dot{J}}{\stackrel{5}{5}}$ & 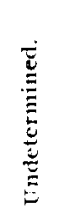 & 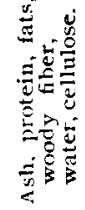 &  \\
\hline roccoli........ 91.69 & $0.5^{8}$ & 2.53 & 1.02 & 0.96 & 0.24 & 2.63 & 0.60 & 96.77 & 3.23 \\
\hline uts. . 89.27 & 0.56 & 2.84 & I. 12 & 1.05 & 0.07 & 4.29 & 0.80 & 94.91 & 5.09 \\
\hline$\ldots \ldots \ldots 80.93$ & 0.06 & 0.13 & 0.02 & 0.09 & $0.0 \mathrm{I}$ & 16.87 & 0.89 & 82.24 & 17.76 \\
\hline b....... 95.25 & 0.56 & $0.6 \mathrm{r}$ & 0.75 & 0.77 & 0.09 & I.74 & 0.23 & 98.03 & 1.97 \\
\hline ......666.13 & 0.23 & 5.59 & 0.23 & 0.14 & $0 . \mathrm{II}$ & 27.90 & $\ldots$ & 72.43 & 27.57 \\
\hline$\ldots \ldots \ldots 66.04$ & 0.70 & 8.82 & 0.45 & 0.82 & 0.19 & 20.53 & 2.45 & 02 & 22.98 \\
\hline gus....... 93.04 & 0.70 & 2.08 & 0.64 & I. I 8 & 0.09 & 2.10 & 0.17 & 97.73 & 2.27 \\
\hline ...... 86.12 & 0.80 & I. 45 & 1.53 & 1.52 & 0.13 & 7.80 & 0.65 & $9 \mathrm{I} \cdot 55$ & 8.45 \\
\hline water) .72 .54 & I. 16 & 3.74 & 0.59 & 0.13 & I. 84 & 18.48 & 1.72 & 79.80 & 20.20 \\
\hline$(\operatorname{milk}) \ldots 64.74$ & I. 55 & 4.39 & 0.40 & 0.84 & 2.10 & $25 \cdot 96$ & 0.02 & 74.02 & 25.98 \\
\hline$\ldots \ldots \ldots 62.18$ & 0.67 & 9.40 & $2.2 \mathrm{I}$ & 2.53 & 0.70 & 23.16 & $\cdots$ & 77.69 & $22.3 \mathrm{I}$ \\
\hline ....8 80.62 & 0.09 & $0.5^{8}$ & 0.03 & 0.04 & 0.03 & I 6.65 & 3.55 & 79.80 & 20.20 \\
\hline chokes.. 84.72 & 1.15 & 2.95 & $1.0 \mathrm{I}$ & 1.70 & 0.26 & 7.68 & 0.53 & 91.79 & 8.21 \\
\hline$s \ldots \ldots \ldots 84.18$ & 0.6 .3 & 4.28 & 2.13 & 1.42 & 0.06 & 8.92 & $\cdots$ & 92.70 & $7 \cdot 30$ \\
\hline Baked beans.....6.69.85 & 1.78 & & 1.20 & 0.20 & 0.19 & 21.69 & 2.10 & 76.21 & 23.79 \\
\hline
\end{tabular}

\title{
INVESTIGATION OF THE BODIES CALLED FIBER AND CARBOHYDRATES IN FEEDING-STUFFS, WITH A TENTATIVE DETERMINATION OF THE COMPONENTS OF EACH. ${ }^{1}$
}

\author{
BY P. SCHWEITZER.
}

Received December 30, z903.

THE results of a continuation and extension of the work of which a preliminary part was published in the Annual Report of the Missouri Agr. Expt. Station for 1898 are here presented. Ten substances-two of corn stalks, two of corn leaves, three of timothy hay, two of red clover, and one of blue grass-were selected for the purpose. The character and composition of these, as ascertained by the Official Agricultural Chemists' method, all determinations being in duplicate and made with great care under conditions as nearly alike for the same groups of bodies

1 Read at the St. Louis meeting of the American Chemical Society. The larger part of the laboratory work was done by Mr. W. B. Cady. 
in the different feeds as it was possible to maintain, are tabulated in Table I. The carbohydrates are, of course, given by difference and, for comparison's sake, the percentages also of the fibers by the chlorate and bromine methods. Both of these methods, described by Dr. Hugo Müller under Pflanzenfaser on pages 26 and 27 of the "Bericht über die Entwickelung der chemischen Industrie, 1877 , by Dr. A. W. Hofmann," were modified, as necessity seemed to require, yet without, it is believed, seriously interfering with the quantitative production of a fairly pure fiber.

The percentages of fiber by the three methods are, as was expected, different and may be compared in Table II, which is calculated for water and ash-free material. The differences in the fibers affect, of course, also the carbohydrates and, while the official and chlorate methods yield results that, by averaging, come near one another, those by the bromine method are much higher for fiber and correspondingly lower for carbohydrates, through retaining the pectose bodies, shown in the published preliminary investigation to be present.

The percentages of ash in the fibers are quite large and are given, along with the nitrogen, as averages for each ten samples at the bottom of the table.

The Ultimate Composition of the fibers ${ }^{1}$ obtained by the three methods is given in Table III, calculated for ash, nitrogen and water-free material; that of the portions dissolved by the Schweizer reagent and precipitated by hydrochloric acid is added for the sake of comparison. It will be seen that in no instance do we deal with chemically pure cellulose; the oxygen falls in twenty-nine of the thirty analyses below the requirements of the hydrogen to form water and it would, therefore, be plainly useless to construct any symbols for the fibers analyzed. The bodies recovered from their solution in the ammoniacal copper solution, likewise, differ slightly from one another, yet, on the whole, they are what $G$. Bumcke and $R$. Wolfenstein ${ }^{2}$ call the lactone of the acid cellulose, the percentage composition of which is closely approached by the average of the three analyses given.

1 The requisite quantity of fiber by each of the three methods was prepared by treating successively 2 grams of the material until about 6 grams of crude fiber was obtained. This, finely ground, furnished the material for this and the other work of the investigation.

${ }^{2}$ Ber. d. ckem. Ges., 32, 4293 . 
If symbols for these compounds were to be offered, they might be as follows:

$$
\begin{aligned}
& \mathrm{C}_{44} \mathrm{H}_{79} \mathrm{O}_{37} \text { by O. A. C. method) Percentage Composition: } \\
& \left.\mathrm{C}_{43} \mathrm{H}_{i 5} \mathrm{O}_{38} \text { by chlorate method }\right\} \mathrm{C}=43.64 \mathrm{H}=6.34 \mathrm{O}=50.02 \\
& \mathrm{C}_{43} \mathrm{H}_{44} \mathrm{O}_{37} \text { by bromine method } \\
& \mathrm{C}_{35} \mathrm{H}_{60} \mathrm{O}_{31} \text { B. \& W.'s lactone. } \quad \mathrm{C}=4.3 .73 \mathrm{H}=6.07 \mathrm{O}=50.20
\end{aligned}
$$

The Calorific Values of the different fibers, ascertained by the bomb-calorimeter with completely dried material, may be averaged for each of the three methods and compared with that for pure cellulose. The official method produces a product richer in carbon than the others caused, probably through retaining a greater quantity of encrusting material; the values, in calories per gram, are:

Fiber by O. A. C. method (average) $\cdots . . .4408$.

Fiber by chlorate method (average) .... 4249.

Fiber by bromine nethod (average) ... 4170 .

Cellulose ....................... ${ }_{42} 20 \%$.

Treatment of the Crude Fiber with the Schweiaer Reagent.The reagent itself was prepared in the following manner: 300 grams of chemically pure copper sulphate were dissolved in 6 liters of water, 30 grams of ammonium chloride added and the copper hyclroxicle precipitated by cautious additions of a dilute solution of sodium hydroxide to slight excess. The precipitate was then washed free from alkali by decantation and dissolved by strong ammonia so as to yield a fluid containing about is per cent. of the latter.

Une-half gram of the water-free fiber was then digested for twenty-four hours in a closed flask of $200 \mathrm{cc}$. capacity with 100 cc. of the ragent with frecuent shaking. Water was then added and the solution filtered through asbestos by meats of the suctionpump ant, after sufficient washing, the resiche dried to constant weicht at from $100^{\circ}$ to $105^{\circ} \mathrm{C}$. The filtrate, in turn, was acidulated with inclrochloric acil and set ande for twenty-four hours, when the liruid was carefully decanted off, and the precipitate fually washed on the filter and dried and weighed. The operations described were in all cases slow and difficult. especially so with the materials from Nos. $I+[1$ and $[425$, as the undissolved residues, as well as the re-precipitated cellulose materials, were all more or less gelatinized and reritired special precautions for 
successful washing. The direct weighing of the two bodies, however, permitted now the estimation, by difference, of the amount of the fiber dissolved by this reagent, as well as the amount kept in solution after acidulation. All operations were conducted as nearly alike in manner, time and strength of solution used, as was possible, and the results may be taken as fairly accurate and comparable.

It is seen from Table IV that the action of the O. A. C. method on the fibers is not as powerful as that of the chlorine and bromine methods; for the average percentage of the fibers undissolved by the former is 14.07 , while amounting to only 2.29 and 3.28 in the cases of the others. Corresponding to these effects, we find the hydrolyzed or inverted portions of the materials by the three methods to be I0.32, I4.14 and 24.96 per cent. of the original amounts operated upon.

Furfural Obtained from Feeds and Fibers.-Two grams of finely ground dry substance were brought into an Erlenmeyer flask of $300 \mathrm{cc}$. capacity, connected with a Liebig condenser and separatory funnel by a 2 -hole rubber stopper, and $100 \mathrm{cc}$. of hydrochloric acid of specific gravity I.06 were added. The flask was then heated on wire gauze so that about $30 \mathrm{cc}$. distilled over every fifteen minutes; with every such portion having passed over, $30 \mathrm{cc}$. of the acid were added so as to enter the flask at about the same rate as the distillate left it, keeping the contents of the flask throughout as near $70 \mathrm{cc}$. as possible. The flask was shaken from time to time to bring down the particles that would adhere to its sides.

The distillation was continued until a drop of the distillate on a slip of filtering paper, moistened with aniline acetate, gave no red coloration, yielding in the cases here described from $250 \mathrm{cc}$. to $350 \mathrm{cc}$. of furfural-containing liquid. The distillate was then neutralized with sodium carbonate, made slightly acid with acetic acid and brought up to $500 \mathrm{cc}$. with a salt solution of 208 grams of salt to the liter, and Io cc. of phenyl hydrazine acetate added (I grams of phenyl hydrazine, 7.5 grams of glacial acetic acid to IOO cc. of solution). The whole was then stirred for onehalf hour with a rubber-tipped stirring rod when the hydrazone began to separate out in fine orange-red crystals; set aside for twenty-four hours, the precipitate was now collected in a Gooch 
crucible on asbestos by aid of the suction-pump and washed with IOO cc. of water; the precipitate being slightly soluble, the same amount of wash-water was used in every instance. The hydrazone could be removed without difficulty from the sides of the beaker by means of the stirring rod, except in a few cases where it seemed to be gummy and had to be dissolved by alcohol; in these the alcoholic liquid was evaporated and the slight residue weighed separately. The suction-pump was run five minutes after washing the main precipitate so as to remove most of the water, when it was placel for three hours in a vacuum oven heated to $65^{\circ}$ to $70^{\circ}$, while a current of dry air passed slowly over it. At the expiration of this time, crucible and contents were cooled and weighed, the contents dissolved with warm alcohol, the crucible dried and weighed again and the difference in weight taken as furfural hydrazone, from which, by multiplication with 0.538 , the furfural itself was derived. The method, as tested with known weights of furfuramicl, especially prepared for this purpose, gave sufficiently reliable and accurate results and was, on the whole, not excessively trouhlesome. ${ }^{1}$

From the values thus obtained the percentages, and weights in grams from so much of the fibers as are contained in 100 grams of the feeds, are found and from these again percentages and quantities of pentosan in the feerls are derived by multiplication with I.84 and given in Table T.

The Determination of Sugar and Starch in the nine samples of feed (the material of No. I 426 had unfortunately given out) was made by washing out the sugar with cold water and inverting it, as also the residue, by the usual (.). A. C. method and making the calculations from the weights of the reduced copper. The correction for starch was made by subtracting from the reduced copper, as found, the quantity of it reduced by the pentosan, $i, e$., the pentosan which was readily invertible, not the portion remaining with the fiber and subsequently determined by treatment with stronger acicl. The values are given in Table VI.

I The furfuramid, nifer recrystallization, was drained, pressed between filtering paper atid catefuly air-drief. One gram of it shond yield 1.0746 grams of futfural. Fixperiment yielded in two trials, taking in each case 0.3 gram $(0.322 .4$ gram of furfural), 0.3012 gram and 0.2959 gram. A thire and fouth detetmination, made with 2 grams of feed (No. I 46 ), to which harl been added 2 grams of furfuramid $(0.2149$ gram furfural), yielded respectively 0.4140 gram and 0.4455 gram furfurit or, subtracting that from the feed itself 0.1822 gram and 0.2157 gram. Considering the diffenlty of obtaining perfectly dry and unilecomposed furfuramid, the results are acceptable. 
The Conclusions of the Investigation are tabulated in Table VII and will be readily understood. The contents of the feeds by the $\mathrm{O}$. A. C. method in fiber and carbohydrates, the latter, of course, by difference, are placed at the head and, below, follow the true values for fiber with such individual carbohydrate components as could be determined by a combination of methods. The true value for fiber is the crude fiber less the furfural-yielding complex retained by it, calculated as pentosan. In this, then, a differentiation in the two groups of bodies occurring in crude fiber has been made, resulting in a more correct value for fiber as well as for carbohydrates. In the table, this pentosan is given separately as fibro-pentosan to indicate its origin.

As pectoses, are counted the substances remaining with the fiber by the bromine method and removable by treatment with acid and alkali, as shown in the paper published in the annual report previously referred to. The fiber values by the $\mathrm{O}$. A. C. method subtracted from those of the bromine method furnished, consequently, the values of pectose which, on comparison, agree fairly well with those from similar material in 1898 . These pectoses are now found to yield furfural as well as the fibers, for on subtracting one fiber from the other we subtract also, of course, the pentosan retained by it and, as the latter fiber yields a much larger amount of this than the former, the difference must be attributed to the pectose complex; it is indicated in the table as pecto-pentosan and made to serve, by difference again, to yield the pentosan derived, in part from sugar and starch, but in the main from the carbohydrates of unknown composition and character present.

A comparison of these three values is not without interest, averaging for the ten feeds as follows:

13.43 per cent. of pentosan from fiber ;

26.23 per cent. of pentosan from pectose ;

54.73 per cent. of pentosan from indefinite carbohydrates.

The need of additional investigation in certain definite directions is seen plainly. 


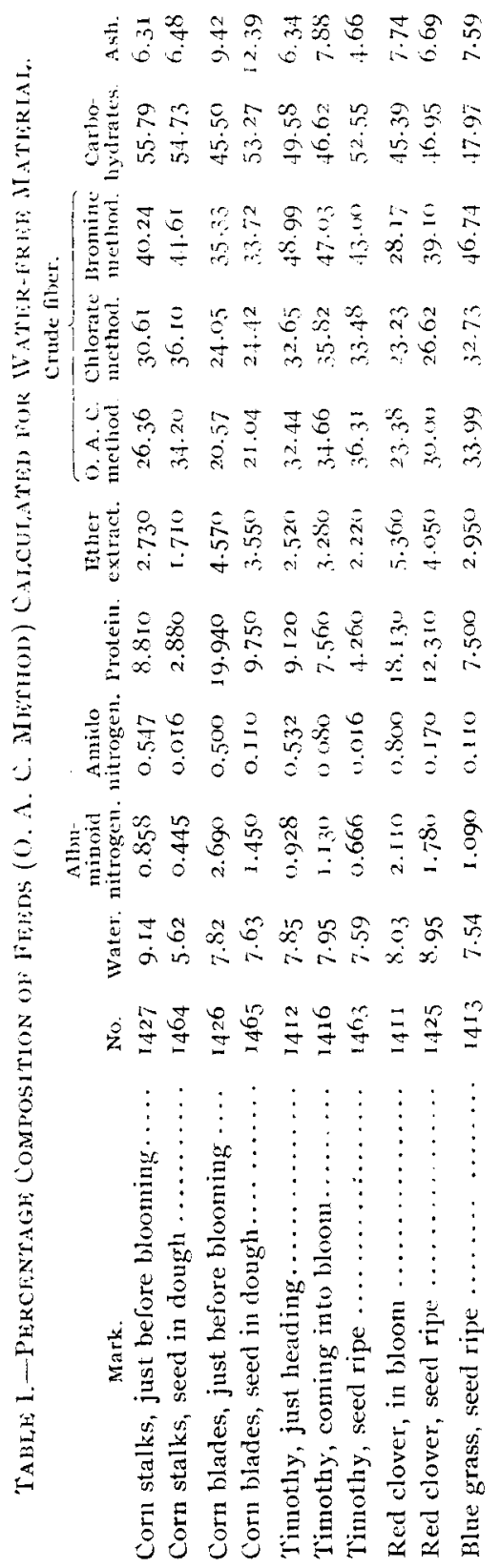


Table II. -Percentages of Crude Fiber and Carbohydrates, CalCULATED FOR ASH AND WATER-FREE MATERIAL.

\begin{tabular}{|c|c|c|c|c|c|c|}
\hline \multirow[b]{2}{*}{ No. } & \multicolumn{2}{|c|}{ O. A. C. method. } & \multicolumn{2}{|c|}{ Chlorate method. } & \multicolumn{2}{|c|}{ Bromine method. } \\
\hline & Fiber. & $\begin{array}{l}\text { Carbohy. } \\
\text { drates. }\end{array}$ & Fiber. & $\begin{array}{l}\text { Carbohy- } \\
\text { drates. }\end{array}$ & Fiber. & $\begin{array}{l}\text { Carbohy } \\
\text { drates. }\end{array}$ \\
\hline 1427 & 28,14 & 59.55 & 32.67 & $55 . \mathrm{OI}$ & 42.95 & 44.73 \\
\hline 1464 & 36.57 & $5^{8.52}$ & 38.60 & 56.49 & 47.70 & $47 \cdot 39$ \\
\hline I 426 & $22.7 \mathrm{I}$ & 50.23 & 26.55 & 46.39 & 39.00 & 33.94 \\
\hline 1465 & 24.02 & 60.80 & 27.87 & 56.94 & 38.49 & 46.33 \\
\hline 1412 & 34.64 & 52.94 & 34.86 & $52.7 \mathrm{I}$ & $52.3 I$ & 35.26 \\
\hline I4I6 & 37.62 & $50.6 \mathrm{I}$ & 38.88 & $49 \cdot 35$ & 51.05 & $37 \cdot 18$ \\
\hline 1463 & 38.08 & 55.12 & 35.12 & 58.09 & $45 \cdot 10$ & 48.10 \\
\hline I 4 II & 25.34 & 49.20 & 25.18 & $49 \cdot 36$ & 30.53 & 44.01 \\
\hline 1425 & 32.15 & 50.32 & 28.53 & 53.94 & 41.90 & $40.5^{6}$ \\
\hline 1413 & $\begin{array}{l}36.78 \\
\text { Aver }\end{array}$ & $5^{1.9 I}$ & $\begin{array}{c}35.42 \\
\text { fasha }\end{array}$ & $\begin{array}{l}55.44 \\
\text { iitrogen }\end{array}$ & $\begin{array}{l}50.5^{8} \\
\text { fibers. }\end{array}$ & 40.28 \\
\hline & 0.705 & & I. 328 & & 0.839 & \\
\hline
\end{tabular}

Table III.-Ultimate Composition of the Crude Fibers by the Thre METhods, Calculated for ash, Nitrogfis, aNd WATER-FREE MATERIAT.

\begin{tabular}{|c|c|c|c|c|c|c|c|c|c|}
\hline \multirow[b]{2}{*}{ No. } & \multicolumn{3}{|c|}{ O. A. C. method. } & \multicolumn{3}{|c|}{ Chlorate method. } & \multicolumn{3}{|c|}{ Bromine method. } \\
\hline & $\begin{array}{l}\text { Car- } \\
\text { bon. }\end{array}$ & $\begin{array}{c}\text { Hydro- } \\
\text { gen. }\end{array}$ & $\begin{array}{l}\text { Oxy- } \\
\text { gen. }\end{array}$ & $\begin{array}{l}\text { Car- } \\
\text { bon. }\end{array}$ & $\begin{array}{c}\text { Hydro- } \\
\text { gen. }\end{array}$ & $\begin{array}{l}\text { Oxy- } \\
\text { gen. }\end{array}$ & $\begin{array}{l}\text { Car- } \\
\text { boll. }\end{array}$ & $\begin{array}{l}\text { Hydro- } \\
\text { gen. }\end{array}$ & $\begin{array}{l}\text { Oxy- } \\
\text { gen. }\end{array}$ \\
\hline 427 & $44 \cdot 35$ & 6.50 & 49.15 & 44.95 & 6.32 & 48.73 & 44.43 & 6.40 & 49. I 7 \\
\hline 1464 & 44.73 & 6.25 & 49.02 & $44.8 I$ & $6.3^{8}$ & $48.8 \mathrm{I}$ & 44.03 & 6.18 & 49.79 \\
\hline 1426 & 44.48 & 6.39 & 49.13 & 42.90 & 6.35 & 50.79 & 44.55 & 6.62 & 48.83 \\
\hline I 465 & 46.17 & 6.74 & 47.09 & 45.12 & 6.39 & 48.49 & 44.79 & 6.57 & 48.64 \\
\hline $\mathrm{I}_{4} \mathrm{I} 2$ & 44.22 & 6.57 & 49.21 & 44.72 & 6.38 & 48.90 & 44. 14 & 6.22 & 49.64 \\
\hline 1416 & 44.47 & 6.48 & 49.05 & $44.9^{8}$ & 6.54 & 48.18 & 44.49 & $6.4 \mathrm{I}$ & 49.10 \\
\hline 1463 & 44.98 & 6.39 & 48.63 & 44.83 & 6.43 & 48.74 & 44.06 & 6.48 & 49.46 \\
\hline I $4 \mathrm{II}$ & 46.55 & 6.42 & 47.03 & 44.43 & 6.39 & 49.18 & 44.61 & 6.50 & 48.89 \\
\hline I 425 & 47.06 & 6.54 & 46.40 & 45.05 & 6.45 & 48.50 & 44.99 & 6.48 & $4^{8.53}$ \\
\hline $\mathrm{I}_{4} \mathrm{I} 3$ & 44.72 & 6.40 & 48.88 & 44.89 & 6.47 & 48.64 & $44.5^{\circ}$ & 6.73 & 48.77 \\
\hline
\end{tabular}

Composition of that part of the fiber dissolved by and reprecipitated from the Schweizer reagent.

$\begin{array}{lllllllll}44.06 & 6.59 & 49.35 & 43.00 & 6.28 & 50.72 & 43.85 & 6.15 & 50.00\end{array}$ 


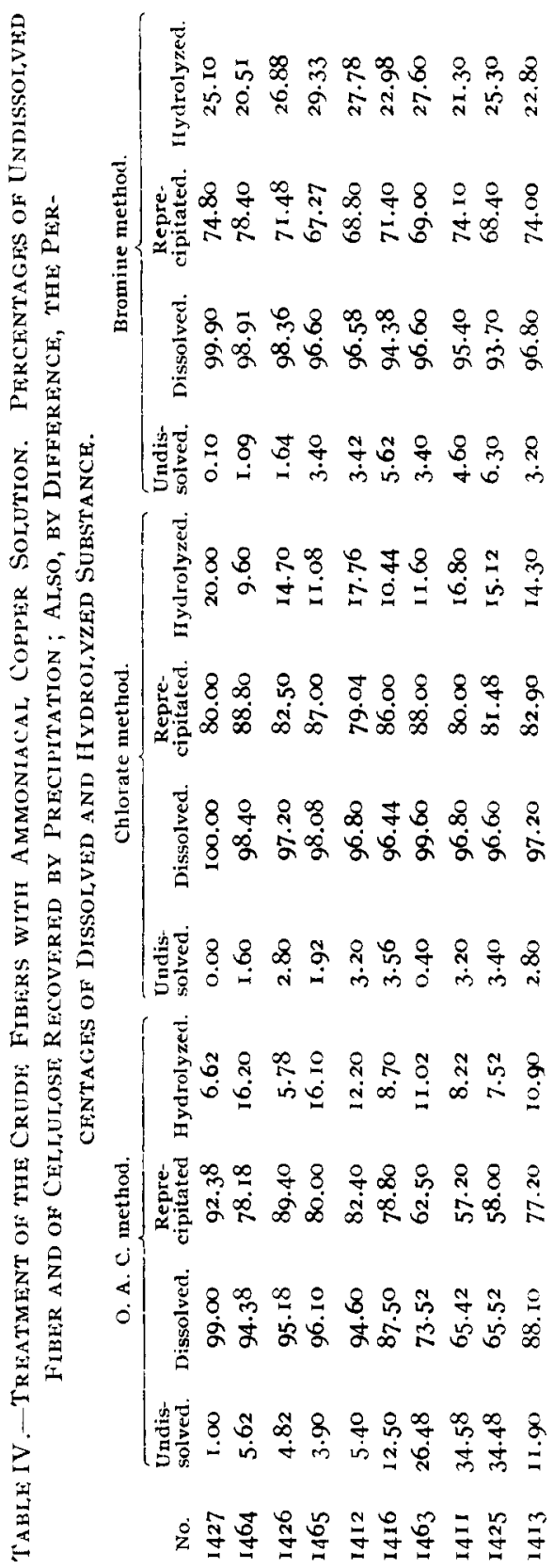


FIBER AND CARBOHYDRATES IN FEEDING-STUFFS. 26 I

Table V.-Per Cent. of Pentosans in Dry and Ash-free Material, Calculated From FURfURal; Factor I.84.

Percent. of pentosan in feed and fiber.

\begin{tabular}{|c|c|c|c|c|c|c|c|}
\hline \multirow[b]{2}{*}{ No. } & \multirow[b]{2}{*}{ Feed. } & \multicolumn{3}{|c|}{ Fibers by } & \multicolumn{3}{|c|}{$\begin{array}{l}\text { Grams of pentosan in fiber } \\
\text { from too grams of feed. }\end{array}$} \\
\hline & & $\begin{array}{l}\text { o. A.C. } \\
\text { method. }\end{array}$ & $\begin{array}{l}\text { Chlorate } \\
\text { method. }\end{array}$ & $\begin{array}{l}\text { Bromine } \\
\text { method. }\end{array}$ & $\begin{array}{l}\text { o.A.C. } \\
\text { method. }\end{array}$ & $\begin{array}{l}\text { Chlorate } \\
\text { method. }\end{array}$ & $\begin{array}{l}\text { Bromine } \\
\text { method. }\end{array}$ \\
\hline 1427 & 23.13 & I6.93 & 13.91 & 25.74 & 3.74 & 4.52 & I $1 . \infty$ \\
\hline 1464 & 27.25 & 14.94 & 16.80 & 24.14 & 5.43 & $6.4 \mathrm{I}$ & I I. 47 \\
\hline I426 & 23.39 & 16.85 & I 7.26 & 29.02 & 3.79 & $4.4 \mathrm{I}$ & I 1.23 \\
\hline I 465 & 25.10 & 15.11 & 19.45 & 30.54 & 3.53 & 5.20 & 11.27 \\
\hline 1412 & 17.46 & 13.21 & I9.34 & 24.49 & $4.5^{6}$ & 6.65 & 12.74 \\
\hline 1416 & 23.15 & I3.OI & $16.7 \mathrm{I}$ & 23.64 & 4.87 & $6.4 \mathrm{I}$ & 12.01 \\
\hline 1463 & 25.23 & I 5.33 & I5.84 & $27 \cdot 5$ I & 5.79 & $5.5 \mathrm{I}$ & 12.34 \\
\hline $\mathrm{I}_{4} \mathrm{II}$ & 14.06 & II.94 & $9.8 \mathrm{I}$ & I 6.87 & 3.00 & 2.44 & 5.11 \\
\hline I 425 & 16.63 & 12.84 & 11.42 & 21.67 & 4. II & 3.23 & 8.96 \\
\hline 1413 & 23.90 & I 3.28 & 19.83 & 26.64 & 4.86 & 6.93 & $13.3^{8}$ \\
\hline Average, & 21.93 & 14.04 & 16.04 & 25.03 & $4 \cdot 37$ & 5.17 & 10.95 \\
\hline
\end{tabular}

Table VI.-PER Cent. of Sugar and Starch in WatFr and AshFREE FEEDS.

$\begin{array}{rcc}\text { Sugar. } & \text { Yer cent. of } & \begin{array}{c}\text { Starch and pentosans } \\ \text { calculated } \\ \text { as starch. }\end{array} \\ 20.69 & \text { Starch. } & \text { I9.39 } \\ 2.31 & \ldots . & 23.56 \\ \ldots . & 1.42 & \ldots \ldots \\ 3.20 & \ldots . . & 23.89 \\ 2.91 & 2.02 & 21.99 \\ 3.16 & 9.24 & 24.96 \\ 3.82 & 6.12 & 26.29 \\ 3.86 & 6.19 & 23.56 \\ 4.58 & 12.01 & 17.46 \\ 3.45 & 4.84 & 24.39\end{array}$




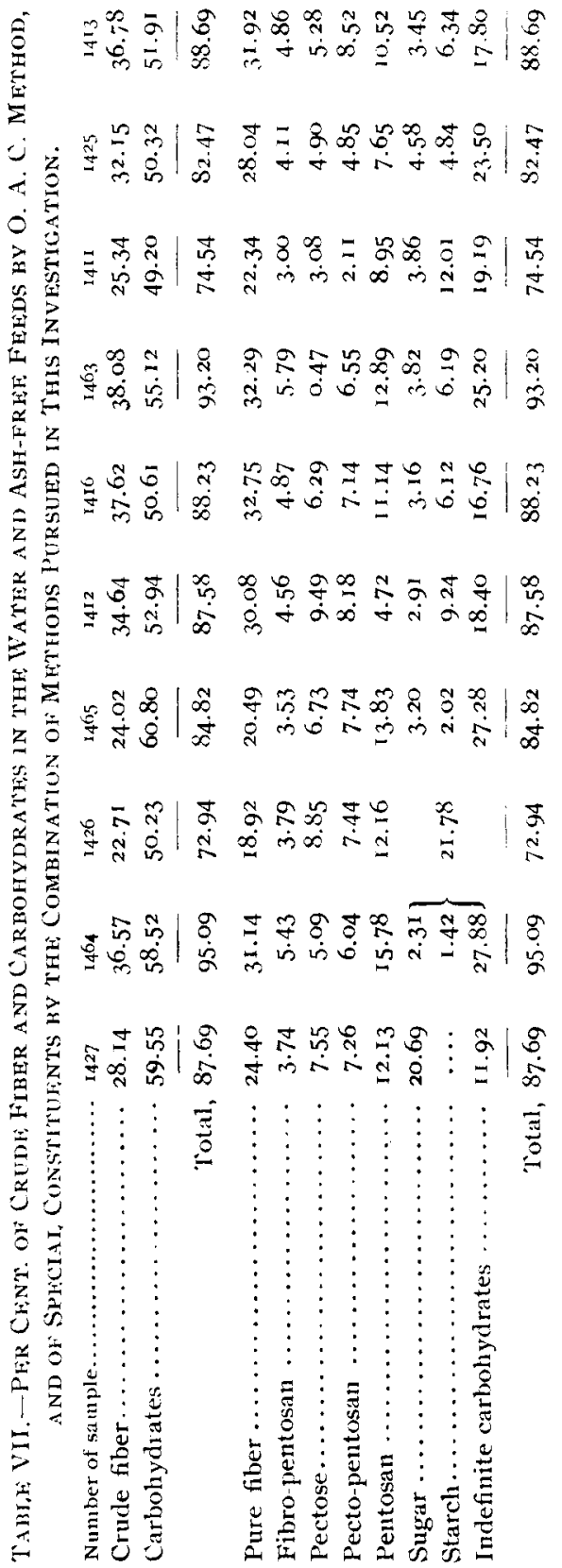

